\title{
Grading Programming Assignments using Rubrics
}

Katrin Becker

\author{
Computer Science Education Group \\ Department of Computer Science \\ University of Calgary \\ 2500 University Dr. N.W. \\ Calgary, Alberta, Canada T2N 1N4 \\ 14032206784 \\ becker@cpsc.ucalgary.ca
}

\section{Categories and Subject Descriptors}

K.3.2 [Computers and Education]: Computer Science Education

\section{General Terms \\ none}

\section{Keywords}

Rubrics; Assessment

\section{INTRODUCTION}

Rubrics are a relatively well understood assessment instrument, although it doesn't appear to be heavily used in CSE. "Learning increases, even in its serendipitous aspects, when learners have a sense of what they are setting out to learn, a statement of explicit standards they must meet, and a way of seeing what they have learned." [Loac86] "Assessment requires [faculty] to articulate... explicit and public statements of criteria of performance. By doing so, faculty refine their own understanding of expected abilities, clarify for their colleagues the basis of their judgment, and enable students to understand what performance is required." [5]

\section{FEEDBACK ON PROGRAMMING ASSIGNMENTS:}

Students learning to program require extensive feedback on their efforts in order to improve their approaches and techniques. An on-going struggle is to strike an appropriate balance between providing sufficient feedback for the students on the one hand, and creating an effective marking guide that can be used in a reasonable amount of time, and yields consistent results when employed by different markers on the other.

In our institution, we must cope with very large first year classes (100-250 per section, multiple sections). This usually necessitates more than one instructor and as many as 22 teaching assistants in one term. Our teaching assistants are typically graduate students with very diverse backgrounds. Providing our students with consistent marking has often been difficult.

\section{RUBRICS}

One solution to this problem is to create relatively detailed rubrics that outline what students must do to meet and exceed the requirements. It can also provide details for what constitutes failure to meet the requirements. The approach we have taken in our first year classes is to create two rubrics for each assignment: one which addresses general style and design issues and one which addresses elements specific to the particular problem being solved. The general rubric is used for all assignments, partly so the markers will become familiar with its contents - as they become more familiar with it, the time they must spend marking will go down.

The rubric is a $2 \mathrm{D}$ grid, where each row describes one element of the program, problem or solution, and each column relates to a level of achievement. Students may choose how much effort they wish to put into an assignment by choosing which elements they with to satisfy. Each 'box' is assigned a value such that the totals of the highest achievements in each row sum to a 'perfect' score. Markers simply highlight the box that applies most closely in each row and then adds up the corresponding values. Each assignment applies two rubrics and the sum of both becomes the student's mark.

\section{EXAMPLES}

[1] General Programming Assignment Rubric: http://pages.cpsc.ucalgary.ca/ becker/233/Asst/Progra mRubric.htm

[2] $1^{\text {st }}$ Assignment (transition from Pascal to Java) Rubric: http://pages.cpsc.ucalgary.ca/ becker/233/Asst/Transit ion/A1-Rubric.htm

[3] Solitaire Game Rubric: http://pages.cpsc.ucalgary.ca/ becker/233/Asst/Solitair e/A3-Rubric.htm

[4] Natural Language Parser Rubric: http://pages.cpac.ucalgary.ca/ becker/233/Asst/Parsing/A4Rubric.htm

COPYRIGHT IS HELD BY THE AUTHOR/OWNER(S).

ITICSE'03, JUNE 30-JULY 2, 2003, THESSALONIKI, GREECE

ACM 1-58813-672-2/03/0006. 
[5] Loacker, G., Cromwell C., \& O'Brien, K. "Assessment in Higher Education: To Serve the Learner." In Adelman, C (Ed.), "Assessment in American Higher
Education" (p47-62). Washington DC: U.S. Department of Education, Office of Educational research and Improvement. 1986, p47, p51 